\title{
Respiratory muscle strength in asthmatic children
}

\section{Alessandra Maria Farias Cavalcante Marcelino', Daniele Andrade da Cunha², Renata Andrade da Cunha ${ }^{3}$, Hilton Justino da Silva ${ }^{4}$.}

\author{
1) Master. Professor \\ 2) $\mathrm{PhD}$. Professor. \\ 3) Master. Student \\ 4) $\mathrm{PhD}$. Professor. \\ Institution: Universidade Federal de Pernambuco - Pós-graduação em Patologia \\ Recife / PE - Brazil. \\ Mailing address: Hilton Justino da Silva - Rua São Salvador, 105 Apto. 1002 - Espinheiro - Recife / PE - Brazil - Zip code: 52020-200 - Telephone: (+55 81) 2126-8927 \\ -E-mail: hdfono@yahoo.com.br \\ Edital Universal CNPq 15/2007. \\ Article received in May 25, 2012. Article approved in July 31, 2012.
}

\section{SUMMARY}

Introduction: Changes in the respiratory system of asthmatics are also due to the mechanical disadvantage caused by the increased airway resistance.

Objective: The study aims to evaluate the respiratory muscle strength and nutritional status of asthmatic children.

Method: This is a prospective descriptive and transversal study with 50 children aged 7 to 12 years, who were placed into 2 groups, asthmatic and non-asthmatic. Respiratory muscle strength was evaluated on the basis of maximal inspiratory pressure (MIP) and maximal expiratory pressure (MEP). The nutritional status was evaluated by measuring the anthropometric data, including height, weight, and body mass index (BMI). The findings were subjected to analysis of variance, chi-square, and Student's $t$ test, and $\mathrm{p}$-values $<0.05$ was considered statistically significant.

Results: In our comparisons, we observed statistically significantly lower values for age, weight, and height in asthmatic patients: $8.52 \pm 1.49$ years, $30.62 \pm 7.66 \mathrm{~kg}$, and $129.85 \pm 10.24 \mathrm{~cm}$, respectively, vs. non-asthmatic children $(9.79 \pm 1.51$ years, $39.92 \pm$ $16.57 \mathrm{~kg}$, and $139.04 \pm 11.62 \mathrm{~cm}$, respectively). There was no significant increase in MIP and MEP between the groups: MIP was $-84.96 \pm 27.52 \mathrm{cmH}_{2} \mathrm{O}$ for the asthmatic group and $-88.56 \pm 26.50 \mathrm{cmH}_{2} \mathrm{O}$ for the non-asthmatic group, and MEP was 64.48 $\pm 19.23 \mathrm{cmH}_{2} \mathrm{O}$ for asthmatic children and $+66.72 \pm 16.56 \mathrm{cmH}_{2} \mathrm{O}$ for non-asthmatics.

Conclusion: There was no statistically significant difference between groups, but we observed that MIP and MEP were slightly higher in the non-asthmatic group than in the asthmatic group.

Keywords: asthma; muscle strength; respiratory muscles.

\section{INTRODUCTION}

Asthma usually begins early (1) and is considered the most common disease in children. It can lead to impaired psychomotor, social, educational, and emotional development (2). There are classic symptoms such as shortness of breath, coughing, and wheezing $(2,3)$, and daily the use of medication should be recommended for all children with moderate to severe asthma, according to guidelines(4).

In general, the medical treatment is administrations of corticosteroids, which may incur the risk of developing steroid-induced myopathy when used for long periods and in high quantities. This myopathy occurs in the peripheral muscles, but its impact on respiratory muscle it is not clear yet $(5,6,7)$.

There are also changes in the respiratory system of asthmatics due to the mechanical disadvantage caused by increased airway resistance (8). Such changes may be responsible for a decrease in respiratory muscle efficiency. One of them is the hyperinflation, which flattens the diaphragm, thereby shortening the inspiratory muscle (8.9). Several studies suggest that hyperinflation negatively affects the efficiency of respiratory muscles in asthmatic adults $(8,9,10)$

This study is important because its objective is to evaluate the respiratory muscle strength in asthmatic children, whereas most studies on pathophysiology and treatment of the disease evolution have until now been performed only in adults (11).

\section{METHOD}

This is a descriptive cross-sectional and individualized study that was developed in the pediatric allergology ambulatory and/or general pediatric clinic of the Hospital das Clínicas, linked to the Universidade Federal of Pernambuco (UFPE), between August 2008 and July 2009. 
The study population included 2 groups: a group of asthmatic children, including 25 children with diagnosis of asthma per the handbook of pediatric ambulatory allergology, who had asthma as the main complaint, and the other group of 25 non-asthmatic children. Their ages were between 7 and 12 years. This age group was selected because this is considered a transition period in the development of the respiratory system and marks the end of pubertal growth and structural changes in the peripheral lung (12). Children who had neurological neurologic impairment, crisis of asthma at the time of evaluation, serious cardiopathies, orthodontic devices, craniofacial abnormalities, and hypertrophy of tonsil and/or adenoids and those whose guardians did not consent were excluded from this study.

In both groups, respiratory muscle strength was evaluated by measuring the maximal inspiratory pressure(MIP) and maximal expiratory pressure (MEP) produced in the mouth during the maximum effort against occluded airway during inspiration and exhalation, respectively, using a portable manuvacuometer (Medical Commercial, Brazil). The children were asked to make a maximal inspiration from the residual volume for the measurement of MIP with the occluded valve. To determine MEP, a maximal exhalation from total lung capacity was performedto register the peak pressure against the valve (13).

Each child performed the procedure, at the most, 5 times, resulting in at least 3 acceptable maneuvers (with no leaks during at least 2 seconds of each maneuver). Then, the highest pressure values in $\mathrm{cmH}_{2} \mathrm{O}$ were compared between the groups. To assess this measure, the children were seated with their nose occluded with a nose clip for inspiration, and exhalation was performed only at the mouth, with the mouthpiece connected to the manuvacuometer.

To evaluate the nutritional status of children in this sample, the distribution of percentiles of body mass index (BMI) was analyzed according to age and sex, obtained using the equation BMI $=$ weight $(\mathrm{kg}) /$ height $\left(\mathrm{m}^{2}\right)$. Weight was recorded using a properly calibrated balance Filizzola ${ }^{\circledR}$ with sensitivity of $1 \mathrm{~kg}$ with each child wearing as little clothing as possible, requiring the registration of the weight in kilograms and grams. Height was measured with the child in a standing position, barefoot, with feet parallel and together; a tape-measure and a square, which was firmly supported on the head were used for measuring the height.

A descriptive analysis was performed to explain the results. The measured variables are presented in tables and include descriptive measures such as minimum, maximum, average, and standard deviation. The Kolmogorov-Smirnov test was applied test the assumption of normality of the variables involved in the study. For the analysis of quantitative variables between asthmatic and non-asthmatic groups, the Student's $t$ test was used, and to analyze the qualitative variables, a chi-square test was used. All the conclusions are based on the significance level of 5\%.

The children's' guardians received clarification about the objectives of this research and were informed that this study was approved by the research ethics committee of the Universidade Federal de Pernambuco; they were requested to sign an assent free and clarified term allowing the child's participation in the study. This work was approved by the ethics committee in research of Universidade Federal de Pernambuco (224/2006).

\section{RESULTS}

The sample in this study consisted of 50 children distributed into 2 groups, the asthmatic and non-asthmatic groups. Table 1 shows the distribution of children evaluated by gender in the asthmatic and non-asthmatic groups. In the asthmatic group, 52\% children were male and 48\% were female, and in the non-asthmatic group, $32 \%$ were male and 68\%were female. Although there were more male children in the asthmatic group, this difference was not significant, so the groups were distributed evenly by gender.

Table 2 shows the distribution of the data for age, weight, height, and BMI in the asthmatic and non-asthmatic groups. The average of age of children in the asthmatic group was $8.52 \pm 1.49$ years and in the non-asthmatic group it was 9.79 years \pm 1.51 years $(\mathrm{p}=0.004)$. The asthmatic group had a mean weight of $30.62 \pm 7.66 \mathrm{~kg}$ and the non-asthmatic group had mean weight of $39.92 \pm$ $16.57 \mathrm{~kg}(\mathrm{p}=0.016)$. Average height was $129.85 \pm 10.24 \mathrm{~cm}$ in the asthmatic children and $139.04 \pm 11.62 \mathrm{~cm}$ in the nonasthmatic children $(p=0.005)$. The average BMI was 17.94

Table I. Distribution of children evaluated for gender in asthmatic and non-asthmatic groups.

\begin{tabular}{lccccc}
\hline Gender & \multicolumn{2}{c}{ Asthmatic } & \multicolumn{2}{c}{ Non-asthmatic } & P-value \\
& $N$ & $\%$ & $N$ & $\%$ & \\
\hline Male & 13 & 52 & 8 & 32 & \\
Female & 12 & 48 & 17 & 68 & 0.252 \\
\hline
\end{tabular}

$\mathrm{N}$-number of children in the group

$\%$ - percentage corresponding to the number of children in the group

Statistical test, chi-square 
Table 2. Distribution of children by age, weight, height, and BMI in asthmatic and non-asthmatic groups.

\begin{tabular}{lcccccc}
\hline & $\mathrm{N}$ & Minimum & Maximum & Average & StandardDeviation & p-value \\
\hline Age(years) & & & & & & \\
$\quad$ Asthmatic & 25 & 7.02 & 11.98 & 8.52 & 1.49 & \\
$\quad$ Non-asthmatic & 25 & 6.27 & 11.90 & 9.79 & 1.51 & 0.004 \\
Weight(kg) & & & & & & \\
$\quad$ Asthmatic & 25 & 18.30 & 49.80 & 30.62 & 7.66 & \\
$\quad$ Non-asthmatic & 25 & 17.70 & 84.50 & 39.92 & 16.57 & 0.016 \\
Height(cm) & & 108 & 149 & 129.85 & 10.24 & \\
$\quad$ Asthmatic & 25 & 118 & 162 & 139.04 & 11.62 & 0.005 \\
$\quad$ Non-asthmatic & 25 & 14.34 & 24.52 & 17.94 & 2.94 & \\
BMI & & 12.09 & 33.03 & 20.08 & 6.26 & 0.133 \\
$\quad$ Asthmatic & 25 & 25 & & & & \\
$\quad$ Non-asthmatic & 25 &
\end{tabular}

$\mathrm{N}$, number of children in the group

Statistical test, Student'st

Table 3. Distribution of inspiratory and peak expiratory pressures in asthmatic and non-asthmatic groups.

\begin{tabular}{lcccccc}
\hline & $\mathrm{N}$ & Minimum & Maximum & Average & StandardDeviation & p-value \\
\hline MIP $\left(\mathrm{cmH}_{2} \mathrm{O}\right)$ & & & & & & \\
Asthmatic & 25 & 32 & 120 & 84.96 & 27.57 & \\
Non-asthmatic & 25 & 30 & 120 & 88.56 & 26.50 & 0.640 \\
MEP $\left(\mathrm{cmH}_{2} \mathrm{O}\right)$ & & & & & & \\
Asthmatic & 25 & 32 & 104 & 64.48 & 19.23 & \\
Non-asthmatic & 25 & 44 & 100 & 66.72 & 16.56 & 0.661 \\
\hline
\end{tabular}

MIP, maximuminspiratory pressure

MEP, maximumexpiratory pressure

Statistical test, Student'st

$\pm 2.94 \mathrm{~kg} / \mathrm{m}^{2}$ in the asthmatic group and $20.08 \pm 6.26 \mathrm{~kg} /$ $\mathrm{m}^{2}$ in the non-asthmatic group $(\mathrm{p}=0.133)$. Thus, the nonasthmatic children had greater age, weight, and height, but no significant differences were found in BMI.

Table 3 shows the distribution of children evaluated for mean inspiratory and peak expiratory pressures in the asthmatic and non-asthmatic groups. The average MIP in the asthmatic group was $84.96 \pm 27.57 \mathrm{cmH}_{2} \mathrm{O}$ and in the non-asthmatic group was $88.56 \pm 26.50 \mathrm{cmH}_{2} \mathrm{O}(\mathrm{p}=$ 0.640 ). The average MEP was $64.48 \pm 19.23 \mathrm{cmH}_{2} \mathrm{O}$ in the asthmatic group and $66.72 \pm 16.56 \mathrm{cmH}_{2}$ Oin the nonasthmatic group ( $\mathrm{p}=0.661)$. It was observed that although the non-asthmatic group showed greater maximal inspiratory and expiratory pressures, there was no statistically significant difference between the groups for MIP and MEP.

\section{DISCUSSION}

Cohen et al. (14) in 1940, observed that the association between asthma and growth inhibition manifested initially as weight loss and if the symptoms persisted, as compromised height and bone maturity. This growth retardation may be associated with early onset asthma, time and severity of the disease, thoracic deformities, hypoxemia, chronic anorexia, corticosteroid use, and socioeconomic status. However, more recent studies concerned with the increase in obesity in the general population have established a relation with asthma; thus, obesity also increases the probability of developing asthma.

In this study, statistically significant values for lower height and weightwerefoundin the asthmatic group compared to the non-asthmatic group, corroborating the work of Cohen et al., without a corresponding change in BMI. All children in the asthmatic group had been taking corticosteroids for a long period of time, but the treatment of asthma as well as the socioeconomic level was low in both groups, which could be correlated with the region where the study was conducted. Thus, the prolonged use 
of steroids or low socioeconomic status may have led to growth retardation, without association with obesity.

We also observed a slight decrease in respiratory muscle strength in asthmatic children compared to nonasthmatic children, but this difference was not statistically significant. It has been proposed by several authors that asthma leads to decreased overall muscle strength especially of the respiratory muscles(6) because of hyperinflation by air trapping that occurs as a consequence to bronchoconstriction $(15,16,17)$ and continuous use and high doses of corticosteroids $(5,6,7)$ for the treatment and control of asthma.

According to Weiner et al., hyperinflation leads to respiratory muscle weakness because it interferes at the insertion of the muscles responsible for the biomechanics of breathing, leading to flattening of the diaphragm and mechanical disadvantage. Corticosteroids in high doses lead to steroid-induced myopathy (5). However, some studies have been establish a relation between long-term corticosteroid treatment even at low doses and decreased muscle strength $(6,7,11)$.

In this study, we could not determine the degree of hyperinflation because the children in prepubertal age are still developing their respiratory framework. They do not show structural changes expected with permanent changes imposed by time, such as imprisonment entrapment of air and increased airway resistance. All had used corticosteroids for long time.

In a literature research for related articles, we found no studies evaluating the impact of asthma and the biomechanical changes in children leading to a decrease in respiratory muscle strength. Only 2 articles that evaluate muscle strength in asthmatic children were found.

Nickerson et al. evaluated the effects of inspiratory muscle training in asthmatic children and compared the MIP values with the values predicted, concluding that children with asthma had reduced respiratory muscle strength and with training, these values were increased. Lands L et al. examined the MIP and nutritional status in children with asthma, cystic fibrosis, and changes in nutritional status and concluded that only the group with cystic fibrosis had decreased MIP, and that this reduction was related to hyperinflation.

Cystic fibrosis has a rapid developmental course and is often more severe than asthma. It is possible that changes in respiratory function, such as hyperinflation will progress more quickly in this group of patients. Furthermore, since this research sample also dealt with children, who, as noted, are still in the process of developing their respiratory framework, not verifying a mechanical disadvantage that would lead to decreased muscle strength. In contrast, studies in adults have shown that the changes in the biomechanics of the thorax are permanent, and the time of exposure to the effects of prolonged use of corticosteroids is higher. Thus, the respiratory muscle weakness becomes more evident $(5,6,15,16,17)$.

Dividing the asthmatic group according to asthma severity would relate the decrease in respiratory muscle strength with asthma in patients with severe asthma. In moderate asthma, where the disease could lead to faster development of mechanical disadvantage, lower MIP and MEP were observed compared to the non-asthmatic group and a sub-group with mild asthmawould be expected.

Overall, there is a scarcity of articles in the literature relating to respiratory muscle strength in asthmatic children. Many studies were performed on adults but there are few studies describing and standardizing respiratory muscle strength in children.

\section{CONCLUSION}

This research proposes further studies monitoring the dosage and duration of corticosteroid use for comparing asthmatic children who are non-users or short-term users of corticosteroids with long-term users. According to the severity of asthma, it is important to have studies relating corticosteroid use with respiratory muscle strength. Studies concerning nutritional status may be more reliable with skinfold measurements, Z-Score, and questionnaires about the child's feeding and may help determine the associations between respiratory muscle strength, nutritional status, and use of corticosteroids.

We suggest that similar samples be allocated in others institutions, making this a multicenter study with no influence of the socioeconomic realities of a particular region, thereby providing a greater chance of increasing the validity of the sample. Moreover, the children in the non-asthmatic groups could be found in schools, daycare centers and other local area without links with hospitals and, thus, unrelated to disease.

\section{REFERENCES}

1. AsherMI, Keil U, Anderson HR, Beasley R, Crane J, Martinez $\mathrm{F}$ et al. International Study of Asthma and Allergies in Childhood (ISAAC): rationale and methods. Eur Respir J. 1995;8:483-91.

2. Pianosi PT, Davis HS. Determinants of physical fitness in 
children with asthma. Pediatrics 2004;113 (3 Pt 1):e225229.

3. Juniper EF, Guyatt GH, Feeny DH, Ferrie PJ, Griffith LE, Townsend M. Measuring quality of life in children with asthma. Quality of Life Research. 1996;5:35-46.

4. National Asthma Education Program: Expert Panel Report II. Guidelines for the Diagnosis and Management of Asthma. Bethesda, MDUS Department of Health and Human Services; 1997. NIH Publication No. 97-4051

5. Decramer M, Lacquet LM, Fagard R, Rogiers P. Corticosteroids contribute to muscle weakness in chronic airflow obstruction. Am J Respir Crit Care Med. 1994;150:1116.

6. Bowyer SL, Lamothe MP, Hollister JR: Steroid myopathy: Incidence and detection in a population with asthma.J Allergy Clin Immunol. 1985;76:234-242.

7. Akkoca O, Mungan D, Karabiyikoglu G, Misirligil Z. Inhaled and systemic corticosteroid therapies: Do they contribute to inspiratory muscle Weakness in asthma? Respiration. 1999;66:332-337.

8. Weiner S, Suo J, Fernandez E, Cherniack RM. The effect of hyperinflation on respiratory muscle strength and efficiency in healthy subjects and patients with asthma. Am Rev Respir Dis. 1990;141:1501-1505.

9. Weiner P, Azgad Y, Ganam R, Weiner M. Inspiratory muscle training in patients with bronchial asthma. Chest. 1992;102:1357-1361.
10. Lavietes MH, Grocela JA, Maniatis T, Potulski F, Ritter AB, Sunderam G. Inspiratory Muscle Strength in Asthma. Chest. 1988;93(5):1043-1048.

11. Bisgaard H. Long-acting $\beta 2$ - agonists in management of childhood asthma: a critical review of the literature. Pediatric Pulmonology. 2000;29:221-34.

12. Merkus PJ, Ten Have-Opbroek AA, Quanjer PH. Human lung growth: a review. Pediatr Pulmonol. 1996;21(6):38397.

13. ATS/ERS. Statement on respiratory muscle test. Am J Resp Crit Care Med. 2002;166:518-624.

14. Cohen MB, Weller RR, Cohen S. Antropometry in children. Progress in allergic children as shown by increments in height, weight and maturity. Am J Dis Child. 1940;60:1058-66.

15. Weiner P, Berar-Yanay N, Davidovich A, Magadle R, Weiner M. Specific inspiratory muscle training in patients with mild asthma with high consumption of inhaled beta(2)agonists. Chest. 2000;117(3):722-7.

16. Gorini M, Iandelli I, Misuri G, Bertoli F, Filippelli M, Mancini $\mathrm{M}$, et al. Chest wall hyperinflation during acute bronchoconstriction in asthma. Am J Respir Crit Care Med. 1999;160(3):808-16.

17. Laghi F, Tobin MJ. Disorders of the respiratory muscles. Am J Respir Crit Care Med. 2003;168(1):10-48. 